\title{
Os direitos reais.
}

\author{
R. Limongi França \\ Docente da Faculdade de Direito da \\ Universidade de São Paulo.
}

\begin{abstract}
Sumário: I - Conceito de Diretto das CoISAS. 1. Doutrina Alienígena. 2. Doutrina Nacional. 3. Conceito que propomos. II - Caracteres do Direito das CoISAs. III Elementos do Direito das Coisas. 1. A lição dos mestres.
\end{abstract}

2. Orientação que propomos.

\section{I - Conceito de direito das coisas}

1. Doutrina Alienígena. Não obstante, inexplicàvelmente, alguns autores do mais elevado coturno, tenham cuidado do Direito das Coisas sem apresentar de início o seu conceito (v. Martin Wolf, Derecho de las Cosas, vol. I, págs. 1-4, "generalidades", trad. de Gronzalez el Alguer, 2. ${ }^{\mathrm{a}}$ ed., Barcelona, 1951; Guido Raffaeldi, Istituzioni di Diritto Civile, pág. 101 e segs., Milano, 1953; Mario Rotond, Istituzioni di Diritto Privato, pág. 224, § 113, 8. ${ }^{\mathrm{a}}$ ed., 1965; Michel de Juglart, Cours de Droit Civil, Tomo I, vol. I, pág. 99 e vol. II, pág. 1, Paris, 1967), dada a sua importância, o mesmo não se deu com outros jurisconsultos, das mais variadas nacionalidades.

É assim, pois, que, entre os germânicos, já ensinava Dernburg que "os direitos reais nos atribuem imediatamente as coisas corpóreas, a êles conexas". E acrescenta: "Nos as "havemos", no sentido jurídico, ainda que não 
lhe tenhamos a efetiva detenção" (Diritti Reali, pág. 76, 192, trad. de Cicala, Torino, 1907).

Ao seu turno, o clássico Venzi, ensina que "estes direitos pertencem... à classe dos direitos patrimoniais, e consistem essencialmente em uma relação entre certa pessoa e determinada coisa, relação que implica um poder ou faculdade que o homem tem sôbre a coisa" (Manuale di Diritto Civile Italiano, pág. 259, Torino, 1928).

De particular interêsse é a lição de JEAN Carbonnier: "é o poder jurídico que tem uma pessoa de retirar diretamente ao todo ou em parte as utilidades econômicas de uma coisa. Na relação de direito que há no direito real, o contacto é imediato entre a pessoa e a coisa... A coisa está como sujeitada à pessoa, obrigada a obedecê-la (de lui obéir), e nisto está o podermos falar em direito sôbre a coisa e fazer, de algum modo, da coisa, um dos dois termos da relação de direito" (Droit Civil, Tomo II, pág. 33, 4. ${ }^{a}$ ed., Paris, 1964).

Entre os autores de língua castelhana, ressaltamos os ensinamentos de ilustre professor da Universidade Central da Venezuela, Manoel Simon Egaña, que, em excelente trabalho especializado assinala que "os direitos reais têm como fundamento. . uma relação entre a pessoa e um objeto de que esta necessita para a satisfação de suas necessidades econômicas". Por outro lado a pessoa é livre (esta facultada) quanto à disposição da coisa, "sem que possa ser perturbada nessa relação pela interferência da conduta dos demais integrantes do grupo social" (Biens $Y$ Derechos Reales, pág. 111, Caracas, 1964).

2. Doutrina Nacional. Entre os reinóis, o grande Mello Freire distingue os direitos em reais e pessoais, mas não lhes apresenta pròpriamente os conceitos: Jam vero jura omnia, cum vel personam, vel rem adficiant, in REALIA, et personali, recte dividuntur. Juris in re species sunt dominius, servitus, pignus. (Institutiones Juris Civilis Lusitani, Lib. III, De Jure Rerum, Tít. I, § XII, Coimbra, 1853). 
Após a Independência, vários autores lusitanos de autoridade no Brasil cuidaram da matéria.

Assim, Borges Carneiro, tratando do direito que podemos ter sôbre as coisas, assinala que o mesmo "ou está inerente à cousa, sem relação a pessoa determinada, ou se refere a uma pessoa determinada". No primeiro caso, acrescenta, a ação que dêle nasce chama-se real (Direito Civil de Portugal, Tomo IV, Livro II, pág. 29, Lisboa, 1867).

Por sua vez, Correa Telles, em cuja obra, a despeito da minúcia com que se ocupou "dos direitos e obrigações, que derivam da propriedade" e de matéria correlata, não apresenta uma noção geral do Direito das Coisas (Digesto Portuguez, Tomo I, $\S \S 732$ e segs., 5. ${ }^{\text {a }}$ ed., Coimbra, 1860).

Não assim no que concerne a CoElHo da Rocha, para quem tais direitos são os "que se exercem sôbre o uso, disposição e posse de uma coisa, os quais os jurisconsultos romanos enumeravam nas diferentes espécies de jus in re" (Instituiçôes de Direito Civil Portuguez, II, pág. 317, 4. ${ }^{a}$ ed., Coimbra, 1857).

Entre nós, Terxeira de Freitas assinala que "há profunda diferença entre os direitos pessoais e os direitos reais, sendo o objeto dêstes uma coisa, e o objeto daqueles um fato" (Esboço, Livro I, vol. 1. ${ }^{\circ}$, pág. 192; Livro III, vol. $4 .^{\circ}$, art. 3.703 e segs., da ed. do Ministério da Justiça, 1952; Cf. "Consolidação das Leis Civis", arts. 884 e segs., 3. a ed., 1875). De particular oportunidade é a lição de Lafayette Rodrigues Pereira, autor de obra prima sôbre o assunto, e cujo ensinamento é o de que - "direito real é o que afeta a coisa direta e imediatamente, sob todos ou sob certos respeitos e a segue em poder de quem quer que a detenha" (Direito das Coisas, I, 21, 5. ${ }^{2}$ ed., 1943).

Em tese especializada sôbre a matéria, Mucio ContiNENTINo, depois de haver passado em revista as principais teorias a respeito, propende pela orientação de Rogurv (La Science Juridique Pure, 3 vols., Paris-Lausanne, 1923), para quem "o direito real é, como os demais direitos, um 
poder-dever, poder do sujeito ativo, juridicamente direto de utilização sôbre uma cousa física, ao qual corresponde o dever do sujeito passivo universal, todos os homens, de se abster de atos contrários ao exercício daquele poder, prestação universal e passiva de não apreensão de uma cousa física" (Direitos Reais, Direitos Pesssoais, pág. 141, Rio de Janeiro, 1935).

3. Conceito que propomos. De quanto se pode observar, através da comparação dos diversos conceitos sôbre o Direito das coisas, quer dos autores estrangeiros quer dos nacionais, a conclusão a que se chega é a de que são fundamentalmente conformes no enunciado do seu ponto de vista.

Alguns, como Venzi, cometem certas imprecisões falando em "faculdade que o homem tem sôbre a coisa". Ora, pode não ser o homem, pessoa natural, senão também os entes coletivos por isso que igualmente são sujeitos de direitos em geral, e em especial, dos direitos reais (v. Manuial, $1 .^{\circ}, 120$ e 147).

Outros, como Carbonnier, referem-se a "utilidades econômicas de uma coisa" e o "contacto imediato entre a pessoa e a coisa". Não fôra preciso dizer, tôda utilidade é econômica (v. Francesco VitTo, Introduzione all'Economia Politica, 9. ${ }^{\mathrm{a}}$ ed., Milano, 1946) e, por outro lado, o contacto da pessoa com a coisa só se entende imediato por fictio juris, pois na realidade, por exemplo, no caso do imóvel locado, o contacto entre o senhorio e o objeto se dá mediata ou indiretamente.

Por outro lado, a generalidade dos jurisconsultos examinados não teve a perspicácia de LAFAYETTE, ao falar em "sob todos ou sob certos respeitos", expressão felicíssima que engloba não só o direito de propriedade, como também os seus desmembramentos.

Em conclusão, propomos o seguinte conceito de direito real: é o direito absoluto (erga omnes), que, tendo por objeto uma cousa corpórea, (qui tangi potest) a submete 
juridicamente de modo direto ao respectivo sujeito, para o fim de sua utilização e disposiçâo, de maneira ampla (propriedade) ou limitada (desmembramentos da propriedade, limitações fideijussorias).

\section{II - Caracteres do direito das coisas.}

Da nossa própria definição podemos deduzir os caracteres básicos do direito das coisas, a saber: A) é um direito absoluto; B) tem por objeto coisa corpórea; C) submete a coisa, jurìdicamente, de modo direto; D) nessa submissão, se subentende a possibilidáde de utilização e de disposição; E) a referida submissão pode ser ampla ou limitada.

Passemos a examiná-los, suscintamente embora.

A) $O$ direito real é de caráter absoluto. Isto quer dizer que, do mesmo modo que os direitos da personalidade, são oponiveis erga omnes.

Por outro lado, advém daí aquilo que LAFAYETTE apresenta como uma característica em apartado (Op. cit., I, 22), a saber o ju's sequendi, ou direito de sequela, i.é., a faculdade do sujeito de exercitar ação para recuperar objeto, contra quem quer que o detenha, jus contra quem libet hujus rei possessorem.

B) Tem por objeto coisa corpórea. Coisa corpórea é aquela que pode ser atingida pelos nossos sentidos, quae tangi potest. No caso, abrange tanto a de natureza móvel como imóvel (v. Manual, 1. ${ }^{\circ}, 188$ e 189).

C) Submete a coisa, juridicamente, de modo direto. Com ef eito, no direito real, o objeto está imediatamente ligado ao sujeito. Êsse liame, porém, pode ser efetivo ou oriundo de uma fictio juris, pois a sua imediatidade se deve entender, num determinado sentido, que permanece mesmo quando um terceiro, preposto ou sujeito de outro direito, esteja na detenção da coisa. 
Não se deve confundir aqui a submissão jurídica imediata, com a posse imediata, o que constitui uma outra categoria (v. de nossa autoria, A Posse no Código Civil, pág. 15, ed. Bushatsky, 1964).

D) Possibilidade de utilização e de disposição. Essa possibilidade é o próprio fundamento do direito real. É o que o justifica de jure naturali, de acôrdo com a lei econômica fundamental de que o homem para conservar a vida e alcançar os fins a que se destina necessita e se utiliza das coisas (v. Francesco VitTo, op. cit., J. Papaterra Limongi, Economia Política, 5. a ed., Freitas Bastos, 1959).

Noutras palavras, é o que diz a respeito Mario Rotondi, quando fala no "contenuto economico" do direito real onde distingue o "valore d'uso" e o "valore di scambio" (Op. cit., pág. 224).

Por outro lado, Manuel Simon Egaña, expondo a doutrina clássica do direito real, assinala que uma das suas diferenças do direito creditício está no fato de que "no puede ser violado mediante una abstención" (Op. cit., pág. 120 , letra $a$ ). Data venia, discordamos, porque o não uso em certas circunstâncias, atenta contra o próprio fundamento e a finalidade do direito real.

E) A submissão do objeto pode ser ampla ou limitada. Ampla se se trata do principal dos direitos reais, a saber, o direito de propriedade. Limitada, se concerne aos direitos reais de uso e gôzo sôbre coisas alheias (enfiteuse, usufruto, uso, habitação, servidões, etc.) ou às adstrições fideijussorias da propriedade (hipoteca, penhor, anticrese, etc.).

Tem-se assinalado ainda que, diferentemente do direito obrigacional, o direito das coisas se adquire por usucapião (EGAÑA, op. cit., 120, letra f). Isto, entretanto, não se aplica a certos direitos reais como as servidões não aparentes e as servidões descontínuas. O mesmo se dirá com referência a todos os direitos reais de garantia. 
Duas importantes observações de Raffaelli colhem no que concerne aos caracteres do Direito das Coisas: A) a necessidade de determinar o interêsse público, no que concerne à possibilidade de uso e gôzo (e, acrescentamos, do não uso); e B) a necessidade de tutelar os interesses privados dos outros sujeitos, prevenindo e impedindo o conflito de interêsses (Istituzioni, pág. 102, letras $a$ e b).

\section{III - Elementos do direito real.}

1. A lição dos mestres. Para Michel DE Juglart, "nous avons, dans tout droit réel, deux elements constitutifs: le sujet et l'objet" (Cours, I, vol. I, pág. 99). No mesmo sentido, Carbonnier, para quem a coisa é, no direito real, "un des deux termes du rapport de droit".

Vários autores, porém, condenam esta orientação pois a mesma importa em dar caráter subjetivo ao objeto (Ortolan, Roguin, Planiol, Ferrara, Cánovas, em suas conhecidas obras).

FGaña (Op. cit.) classifica numa terceira posição a autores como Becker, Barassi, Messineo e Von Tuhr, cuja orientação seria eclética. Guardadas as diferenças do modo de expor a matéria, por cada qual dêsses mestres, o fulcro dessa orientação está em distinguir dois aspectos no direito real: A) o interno; e B) o externo.

Do ponto de vista interno, não haveria negar a relação direta entre a pessoa e a coisa. Do ponto de vista externo, fôra de considerar-se a obrigação geral de abstenção de todos os demais sujeitos.

2. Orientação que propomos. A nosso ver, no direito real devemos considerar quatro elementos: A) o sujeito ativo; B) o sujeito passivo; C) o objeto; e D) a relação jurídica. 
Não há nisto qualquer vêso de cairmos na orientação monísta de Gaudemet e de Saiteilles (do primeiro, Théorie Générale des Obligations, reimpressão, 1965; do segundo, Théorie Générale de l'Obligation, $3 .^{\mathrm{a}}$ ed., 1925), pois já falamos dos caracteres dos direitos reais e, no volume $4 .^{\circ}$, Tomo I, pág. 82, do Manual do Direito Civil, assinalamos as diferenças entre o Direito Real e o Obrigacional. Por outro lado, se levarmos a matéria às suas últimas conseqüências, não há sentido em falarmos no monismo tão sòmente do Direito Patrimonial (Cf. Carbonnier, Op. cit), porque, segundo determinada perspectiva, todo o direito se deve encarar segundo uma concepção monista, pois envolvendo sempre a questão do meu e do seu, as suas técnicas fundamentais são as mesmas, quer para o Direito Público, quer para o Direito Privado (v. LÉon Duguit, Manuel de Droit Constitutionnel, 66, Paris, 1907; Roger Bonnard, Précis de Droit Public, pág. 1, Paris, 1939; de nossa autoria, Formas e Aplicação do Direito Positivo, págs. 17 e segs., ed. da Rev. dos Tribunais, 1969).

A) Sujeito Ativo. São os sujeitos de direito em geral, abrangendo inclusive os incapazes, devidamente representados por quem de direito e, nos atos de disposição, assistidos pelo Estado, através do órgão do Ministério Público.

B) Sujeito Passivo. Tôdas as demais pessoas, em virtude da obrigação, de caráter negativo, de não turbar o exercício do direito real, por parte do sujeito ativo. Por vêzes, entretanto, o sujeito passivo é determinado, como no caso das servidões e dos direitos de vizinhança.

C) Objeto. Já vimos que se trata de coisa corpórea. A energia elétrica e mesmo atômica são igualmente coisas corpóreas, pois constituem res quae tangi possunt. As coisas incorpóreas, como os direitos pessoais, e a impròpriamente denominada "propriedade imaterial", refogem ao espectro do Direito das Coisas, inserindo-se ora no campo dos 
Direitos Privados da Personalidade (Manual, $1^{\circ}$, Livro III), ora no dos Direitos Obrigacionais (vol. IV. Tomo I e II).

D) Relação Jurídica. Já vimos que a sua natureza é direta e em que sentido se deve entender essa expressão. Por outro lado, já se examinou o seu conteúdo que, conforme ficou esclarecido, abrange a faculdade de utilização e de disposição. 